\title{
Lymphangioleiomyomatosis: About Two Cases and Review of the Literature
}

\author{
D Zagaouch*, M El Yahiyaoui, K Marc \\ Pneumology Department, Ibn Sina University Hospital Center, Morocco
}

Submission: August 07, 2021; Published: August 25, 2021

*Corresponding author: Zagaouch Dalal, Pneumology Department, Moulay Youssef Hospital, Ibn Sina University Hospital Center, Rabat, Morocco.

\section{Summary}

Lymphangioleiomyomatosis (LAM) is a rare pulmonary disease of unknown etiology, which affects exclusively the young woman. LAM is associated with much morbidity and can lead to respiratory failure and death unless lung transplantation is performed. The proliferation of abnormal smooth muscle cells (LAM cell) in the lungs, causes destruction of the cystic parenchyma and chronic respiratory failure. The main manifestations are respiratory, revealed by pneumothorax and or chylothorax. The definitive diagnosis is based on the lung biopsy, but in the absence of the latter, criteria diagnostics have been proposed based mainly on the CT aspect, and the presence of renal angiomyolipoma's. The treatment is mainly symptomatic. Sirolimus appears to stabilize respiratory function and improve symptoms, while hormonal treatment is in progress evaluation. However, transplantation remains the only validated treatment. We report two cases of two women with LAM, with different circumstances of discovery and evolution.

Keywords: Lymphangioleiomyomatosis; Cystic pulmonary disease; Pneumothorax; Angiomyolipoma; Tuberous sclerosis complex

Abbreviations: LAM: Lymphangioleiomyomatosis; TSC: Tuberous Sclerosis Complex; Mtor: Mammalian Target of Rapamycin; ARBs: Angiotensin II Receptor Blockers; ATS: American Thoracic Society; FEV1: Forced expiratory volume 1; LTOT: Long-Term Oxygen Therapy; VEGF-D: Vascular Endothelial Growth Factor -D

\section{Introduction}

Lymphangioleiomyomatosis is a rare, slow and progressive cystic disease, reported mainly in woman of childbearing age, either sporadically or in the context of Tuberous sclerosis complex (LAM-TSC) [1-2]. The prevalence of the sporadic form is estimated to be around 1 in 400,000 adult women. There is no specific curative treatment for LAM. However, early diagnosis and treatment of complications improves quality of life [3-4]. Patients with LAM usually develop progressive dyspnea and recurrent pneumothorax, chylous collections and occasional hemoptysis [1-5]. Currently, no effective treatment for LAM is available [6]. Only sirolimus, which blocks the Mammalian target of rapamycin (mTOR) pathway, appears to stabilize respiratory function and improve symptoms [7]. For advanced forms of the disease, lung transplantation is the only possible remedy, with a risk disease recurrence [8].

\section{Observations}

\section{Observation 1}

This is a young patient aged 29, married, mother of a child, pastry chef, without any particular personal or family pathological history and having no particular exposure, especially to tobacco, who has presented for two years (4 months after giving birth), progressively worsening dyspnea on exertion classified as stage IV of mMRC on admission, associated with an intermittent dry cough with no other associated respiratory or extra-respiratory signs. Clinical examination finds patient with polypnea, $\mathrm{SpO}_{2}$ of $90 \%$ in ambient air with bilateral basithoracic crackles, without digital hippocratism, nor cutaneous lesions. X-ray of the thorax shows bilateral lucencies (Figure 1) and the CT chest scan reveals the presence of diffuse thin-walled cystic lesions, evenly distributed over the two pulmonary areas (Figure 2).

The electrophoresis of proteins as well as the dosage of immunoglobulins was normal (IgG: 10g/l, IgA: 2g/l, IgM: 1g/l). Abdomino-pelvic ultrasound revealed a renal angiomyolipoma measuring less than $4 \mathrm{~cm}$ (Figure 3). A neurological examination and the cerebral CT as well as the dermatological examination and ophthalmologic examination for Tuberous sclerosis complex (TSC) did not detect any anomaly. Gas testing revealed hypoxemia at $52 \mathrm{mmHg}$ and hypocapnia at $33 \mathrm{mmHg}$. The plethysmography and the transfer factor of carbon monoxide (DLCO) measurement could not be performed. Cardiac echocardiography did not 
show any abnormalities in favor of pulmonary hypertension. The diagnosis of definite LAM was retained according to the international ERS guidelines: the compatible aspect on the chest CT scan and the presence of renal angiomyolipoma.

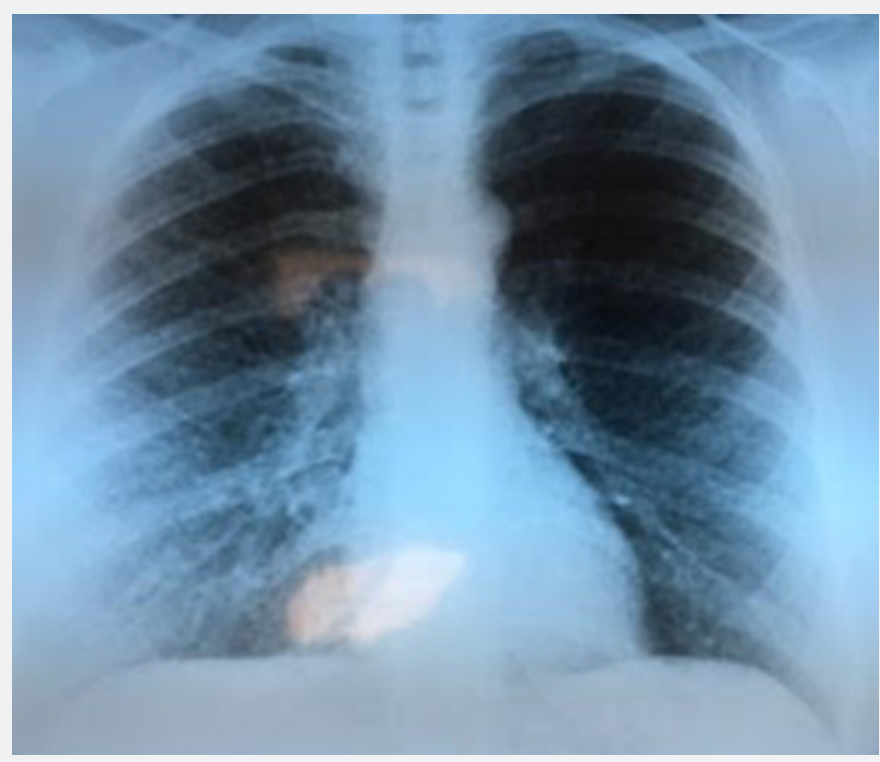

Figure 1: X-ray of the thorax shows bilateral lucencies.



Figure 2: Thin-walled cystic lesions on chest CT scan, evenly distributed over the two pulmonary areas.

\section{Observation 2}

This is a 56-year-old patient, postmenopausal for two years, childless, non-smoking, monitored for arterial hypertension under angiotensin II receptor blockers (ARBs) and hypothyroidism under Levothyrox, as well as a newly discovered prolactin pituitary adenoma treated with bromocriptine, who has presented for 3 years with progressively worsening exertional dyspnea, currently classified as stage III of mMRC, accompanied by an intermittent dry cough. The clinical examination found a eupneic patient at rest, with an $\mathrm{SpO}_{2}$ of $93 \%$ at rest in the ambient air, without digital hippocratism, nor skin lesions. Pleuropulmonary auscultation is normal.

The functional respiratory assessment objectified a decrease in DLCO to $56 \%$ with preserved air volumes and air flows, 
measured by plethysmography (FEV1 105\%, FEV1 / FVC 0.81 and TLC at 108\%), as well as hypoxemia on gas measurement at $61 \mathrm{mmhg}$. The rest of the biological assessment was negative (in particular the dosage of immunoglobulins), as was the evaluation of cardiac function which did not show pulmonary hypertension. The vascular endothelial growth factor -D (VEGF-D) assay could not be performed. Cerebral and abdominal CT scans found neither intracerebral calcifications nor renal angiomyolipoma's, respectively. The diagnosis of probable sporadic LAM (S-LAM) was made, based on the compatible clinical picture and the characteristic CT aspect which revealed diffuse cystic lesions of less than $2 \mathrm{~cm}$ (Figure 4 ), after ruling out the Tuberous sclerosis complex.

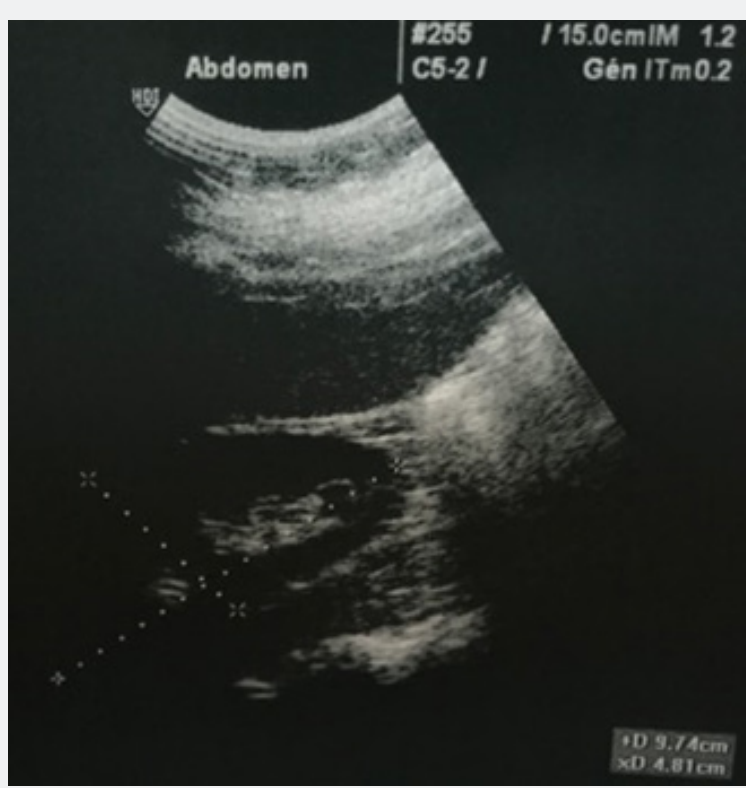

Figure 3: Abdomino-pelvic ultrasound showing a renal angiomyolipoma measuring less than $4 \mathrm{~cm}$.



Figure 4: Chest CT scan revealing diffuse cystic lesions of less than $2 \mathrm{~cm}$.

\section{Discussion}

Cystic lung disease is a distinct group of rare lung diseases, with a diagnosis differential which includes lymphangioleiomyomatosis
(LAM), Birt-Hogg-Dube syndrome, pulmonary Langerhans cell histiocytosis, light chain deposition disease, and other entities still rarer [3-21]. In the lungs, LAM is characterized by progressive infiltration of lung tissue by atypical smooth muscle cells resulting 
in cystic destruction of the lung parenchyma, abnormalities respiratory function, dyspnea and recurrent pneumothorax. In most patients, LAM is manifested at a mean age of 39 years, first with progressive dyspnea or recurrent pneumothorax. She can sometimes be discovered incidentally on a CT scan performed for another reason [3-9].

Extra thoracic involvement includes benign kidney tumors called angiomyolipoma's, chylous pleural and peritoneal effusions, thoracoabdominal lymphadenopathy, and chylous abdominal masses called lymphangioma [10-11]. LAM is characterized on a chest CT scan by multiple air-filled cysts with thin walls, rounded and well delimited, without other significant pulmonary involvement. Cysts are usually small, with walls very thin or not visible, and evenly distributed in all lung fields without zonal predominance, such than observed in the two cases we present (Figures 2 and 4). However, although imagery is typical, the CT alone is insufficient to establish a definite diagnosis of LAM, and additional criteria are required. The ERS recommendations proposed a set of scannographic, clinical and histological criteria to establish the diagnostic (Table 1) [5].

Table 1: Diagnostic criterion for LAM according to international ERS 2010 guidelines.

\begin{tabular}{|c|c|}
\hline \multirow{6}{*}{ LAM certain } & $\begin{array}{l}\text { 1. Characteristic }{ }^{\mathrm{a}} \text { or compatible }{ }^{\mathrm{a}} \text { chest CT scan and lung biopsy fulfilling the histopatholog- } \\
\text { ical criteria of LAM }\end{array}$ \\
\hline & OR \\
\hline & 2. Characteristic ${ }^{\mathrm{a}}$ chest $\mathrm{CT}$ and one of the following: \\
\hline & - angiomyolipoma (kidney) ${ }^{\mathrm{b}}$ \\
\hline & - thoracic or abdominal ${ }^{\mathrm{c}}$ chylous effusion \\
\hline & - lymphangioleiomyoma ${ }^{d}$ or lymphadenopathy affected by LAM ${ }^{\mathrm{d}}-\mathrm{TSC}$ definite or probable \\
\hline \multirow{4}{*}{ LAM probable } & 1. Characteristic ${ }^{\mathrm{a}}$ chest $\mathrm{CT}$ and compatible clinical picture \\
\hline & OR \\
\hline & 2. Compatibility chest scanner and one of sss the following: - angiomyolipoma (kidney) ${ }^{\mathrm{b}}$ \\
\hline & - thoracic or Abdominal ${ }^{c}$ chylous effusion \\
\hline LAM possible & Characteristic $^{\mathrm{a}}$ or compatible chest CT scan \\
\hline \multicolumn{2}{|r|}{ Notes: } \\
\hline \multicolumn{2}{|c|}{$\begin{array}{l}\text { a) Characteristic: several well-defined, thin-walled air-filled cysts, with preserved or increased lung volumes, without other significant pulmonary } \\
\text { involvement (except multifocal micronodular hyperplasia of pneumocytes in patients with TSC); Compatible: as above but only a few cysts ( } 2 \text { to } 10 \text { ). }\end{array}$} \\
\hline \multicolumn{2}{|c|}{ b) diagnosed by characteristic CT scan and / or histopathological examination. } \\
\hline \multicolumn{2}{|c|}{ c) based on visual and / or biochemical characteristics. } \\
\hline \multicolumn{2}{|r|}{ d) based on histopathology. } \\
\hline \multicolumn{2}{|r|}{ e) see reference [7]. } \\
\hline \multicolumn{2}{|c|}{ f) pneumothorax (multiple / bilateral) and / or impairment of lung function as in the LAM } \\
\hline
\end{tabular}

Angiomyolipomas are present in $50 \%$ of patients with S-LAM and in more than $80 \%$ with an LAM-TSC [12], hence the interest of carefully looking for a TSC according to international criteria [10], including a detailed examination of the skin, eyes and nervous system, and brain imaging. We regret however the unavailability of the serum dosage of VEGF-D in order to support our diagnosis such as proposed in the international American Thoracic Society (ATS) recommendations [11]. Indeed, these recommendations are based on studies finding a specificity of $100 \%$ and a sensitivity of $73 \%$ relative to this assay in LAM, thus making it possible to identify it among other pulmonary cystic diseases without resorting to a lung biopsy [13]. On the respiratory functional level,
LAM is mainly characterized by a decrease in the transfer factor of carbon monoxide (DLCO) and obstructive ventilatory disorder, present in $80 \%$ and $50 \%$ of cases, respectively at diagnosis $[3$, $12,14]$.

The mean annual decrease in Forced expiratory volume in one second (FEV1) has been reported between 60 and $120 \mathrm{ml}$ per year in various retrospective studies [15]. Functional monitoring is recommended every 3 to 6 months in the first year or if disease progression is observed, and every 6 to 12 months if disease seems stable [5]. In our two patients, the diagnosis of LAM was discovered after different circumstances, in the first patient, the diagnosis was made at the stage of chronic respiratory failure 
and Long-term oxygen therapy (LTOT), and in the other patient after menauposis which having moderate respiratory signs. The diagnosis of LAM was retained on the compatible scannographic aspect. Unfortunately, the VEGF-D assay could not be performed.

Therapeutically, as directed by the American Thoracic Society (ATS) and the Japanese Respiratory Society (JRS), sirolimus is recommended for people with reduced lung function (FEV1 less than $70 \%$ expected) or rapidly declining (loss of FEV1 more than $90 \mathrm{ml}$ per year) or who have symptoms, chylothorax and chylous ascites [15] and recommended in patients with renal failure in the setting of sporadic LAM [16]. By cons, hormonal treatments (including oophorectomy, progesterone, antiestrogens and GHRH) have been widely used in LAM, but discordant results have been reported [4,17], and no randomized trials are available. These treatments are no longer recommended [14].

Preferred contraceptive methods include progestins alone or intrauterine devices. Patients with LAM should be informed of the high risk of pneumothorax, and sympqtoms of bleeding from LAM such as abdominal pain, hematuria, palpable abdominal mass, and should seek emergency medical attention if such symptoms appear [5]. The risk of bleeding reaches $50 \%$ when the tumor exceeds $4 \mathrm{~cm}$ or if a vascular aneurysm> $5 \mathrm{~mm}$ is present. The LAM is more prone to bleeding in LAM-TSC than in LAM-S [6]. Close monitoring was recommended, and hygienic-dietetic advice was given. Influenza and pneumococcal vaccinations were prescribed in our two patients. Long-term oxygen therapy and lung transplantation were indicated in the first patient while the second patient was referred for follow-up to a specialized center abroad.

The course of the disease is extremely variable, however, half of the patients have stage 3 dyspnea of mMRC ten years after the onset of symptoms [18]. In a recent large study, the 10-year transplant-free survival was $86 \%$ and the median transplant-free survival was 29 years from first symptoms, and 23 years since diagnosis [19]. Pulmonary hypertension is rare and moderate in LAM, and probably results from loss of lung parenchyma and hypoxia (group III) [20].

\section{Conclusion}

The diagnosis of LAM must be one of the etiologies to be evoked in front of an aspect of cystic lung on the scanner thoracic and must benefit from a complete lesional and etiological assessment in order to rule out other etiologies or form associated with Tuberous sclerosis complex. The two cases that we present illustrate, on the one hand, their circumstances of discovery and their different evolutionary profiles, and on the other hand the heterogenicity of this pathology, which makes the diagnosis sometimes difficult. Our work demonstrates the benefit of a detailed analysis of high-resolution chest CT without resorting to lung biopsy to diagnose LAM.

\section{References}

1. Johnson S (1999) Lymphangioleiomyomatosis: clinical features, management and mechanisms. Thorax 54(3): 254-264.

2. Franz DN, Brody A, Meyer C J Leonard, G Chuck, et al. (2001) Mutational and radiographic analysis of compatible lung disease with lymphangioleiomyomatosis and micronodular pneumocytic hyperplasia in women with tuberous sclerosis. Am J Respir Crit Care Med 164(4): 661-668

3. Urban T, Lazor R, Lacronic J, M Murris, S Labrune, et al. (1999) Pulmonary lymphangioleiomyomatosis. A study of 69 patients. Group of Studies and Research on "Orphan" Pulmonary Diseases (GERM “O” P). Medicine (Baltimore) 78(5): 321-337.

4. Johnson SR, Tattersfield AE (1999) Decline in lung function in lymphangioleiomyomatosis: Relation to menopause and progesterone treatment. Am J Respir Crit Care Med 160(2): 628-633.

5. Johnson SR, Cordier JF, Lazor R, Cottin V, Costabel U, et al. (2010) European respiratory society guidelines for the diagnosis and management of lymphangioleiomyomatosis. Eur Respir J 35(1): 14-26.

6. Taveira-DaSilva AM, Stylianou MP, Hedin CJ, Hathaway O, Moss J (2004) Decline in lung function in patients with lymphangioleiomyomatosis treated with or without progesterone. Chest 126(6): 1867-1874

7. Mc Cormack FX, Inoue Y, Moss J, Lianne GS, Charlie S, et al. (2011) Efficacy and safety of sirolimus in lymphangioleiomyomatosis. N Engl ] Med 364(17): 1595-1606

8. Karbowniczek M, Astrinidis A, Balsara BR, Joseph RT, James HL, et al. (2003) Recurrent lymphangiomyomatosis after transplantation: genetic analyses reveal a metastatic mechanism. Am J Respir Crit Care Med 167(7): 976-982.

9. Johnson SR, Taveira-DaSilva AM, Moss J Lymphangioleiomyomatosis. Clin Chest Med 37(3): 389-403.

10. Northrup H, Krueger DA (2013) Tuberous sclerosis complex diagnostic criteria update: Recommendations of the 2012 international tuberous sclerosis complex consensus conference. Pediatr Neurol 49(4): 243254.

11. Mc Cormack FX, Gupta N, Finlay GR, Young LR, Taveira-DaSilva AM, et al (2016) Official american thoracic society/Japanese respiratory society clinical practice guidelines: Lymphangioleiomyomatosis diagnosis and management. Am J Respir Crit Care Med 194(6): 748-761.

12. Ryu JH, Moss J, Beck GJ, Lee JC, Brown KK, et al. (2006) The NHLBI lymphangioleiomyomatosis registry: Characteristics of 230 patients at enrollment. Am J Respir Crit Care Med 173(1): 105-111.

13. Young LR, Vandyke R, Gulleman PM, Inoue $\mathrm{Y}$, Brown $\mathrm{KK}$, et al (2010) Serum vascular endothelial growth factor-d prospectively distinguishes lymphangioleiomyomatosis from other diseases. Chest 138(3): 674-681.

14. Lazor R, Valeyre D, Lacronique J, Wallaert B, Urban T, et al (2004) Low initial KCO predicts rapid fev1 decline in pulmonary lymphangioleiomyomatosis. Respir Med 98(6): 536-541.

15. Harari S, Torre O, Cassandro R, Moss J (2015) The changing face of a rare disease: lymphangioleiomyomatosis. Eur Respir J 46(5): 14711485 .

16. Krueger DA, Northrup H (2013) Tuberous sclerosis complex surveillance and management: recommendations of the 2012 International Tuberous Sclerosis Complex Consensus Conference. Pediatr Neurol 49(4): 255-265. 
17. Yeoh ZW, Navaratnam V, Bhatt R, McCafferty I, Hubbard RB, et al. (2014) Natural history of angiomyolipoma in lymphangioleiomyomatosis: Implications for screening and surveillance. Orphanet J Rare Dis 9:151.

18. Johnson SR, Whale CI, Hubbard RB, Lewis SA, Tattersfield AE (2004) Survival and disease progression in UK patients with lymphangioleiomyomatosis. Thorax 59(9): 800-803.

19. Oprescu N, Mc Cormack FX, Byrnes S, Kinder BW (2013) Clinical predictorsofmortalityand cause of deathinlymphangioleiomyomatosis: A population-based registry. Lung 191(1): 35-42.
20. Freitas CSG, Baldi BG, Jardim C, Araujo MS, Sobral JB, et al. (2017) Pulmonary hypertension in lymphangioleiomyomatosis: Prevalence, severity and the role of carbonmonoxide diffusion capacity as a screening method. Orphanet J Rare Dis 12(1): 74

21. Daccord C, Nicod LP, Lazor R (2017) Cystic Lung Disease in Genetic Syndromes with Deficient Tumor Suppressor Gene Function. Respiration 94(6): 467-485.
Your next submission with Juniper Publishers will reach you the below assets

- Quality Editorial service

- Swift Peer Review

- Reprints availability

- E-prints Service

- Manuscript Podcast for convenient understanding

- Global attainment for your research

- Manuscript accessibility in different formats

( Pdf, E-pub, Full Text, Audio)

- Unceasing customer service

Track the below URL for one-step submission https://juniperpublishers.com/online-submission.php 